\title{
Intracellular Sorting and Processing of a Yeast Vacuolar Hydrolase: Proteinase A Propeptide Contains Vacuolar Targeting Information
}

\author{
DANIEL J. KLIONSKY, LOIS M. BANTA, AND SCOTT D. EMR* \\ Division of Biology, 147-75, California Institute of Technology, Pasadena, California 91125
}

Received 26 October 1987/Accepted 11 February 1988

\begin{abstract}
An inactive precursor form of proteinase $A(\operatorname{PrA})$ transits through the early secretory pathway before final vacuolar delivery. We used gene fusions between the gene coding for PrA (PEP4) and the gene coding for the secretory enzyme invertase (SUC2) to identify vacuolar protein-sorting information in the PrA precursor. We found that the 76-amino-acid preprosegment of $\operatorname{PrA}$ contains at least two sorting signals: an amino-terminal signal peptide that is cleaved from the protein at the level of the endoplasmic reticulum followed by the prosegment which functions as a vacuolar protein-sorting signal. PrA-invertase hybrid proteins that carried this sequence information were accurately sorted to the yeast vacuole as determined by cell fractionation and immunolocalization studies. Hybrid proteins lacking all or a portion of the PrA prosegment were secreted from the cell. Our gene fusion data together with an analysis of the wild-type PrA protein indicated that $\mathrm{N}$-linked carbohydrate modifications are not required for vacuolar sorting of this protein. Furthermore, results obtained with a set of deletion mutations constructed in the PrA prosegment indicated that this sequence also contributes to proper folding of this polypeptide into a stable transit-competent molecule.
\end{abstract}

The secretory pathway in eucaryotic cells mediates the sorting and modification of an array of intracellular and extracellular proteins. Proteins which are synthesized at the level of the endoplasmic reticulum (ER) are either secreted from the cell or specifically retained in distinct subcellular locations such as the ER, Golgi complex, lysosome, or plasma membrane. In the yeast Saccharomyces cerevisiae, proteins destined for delivery to the lysosomelike vacuole also traverse a portion of the secretory pathway. Delivery of enzymes to the vacuole provides a useful system to study protein targeting; vacuolar proteins must be sorted from other secretory proteins during transit through the ER and Golgi complex. Proteins or peptides that lack any apparent delivery signals other than an amino-terminal signal peptide can be secreted from yeast and mammalian cells $(21,24,55$, 59). This suggests that secretion occurs by a default mechanism. Proteins which are diverted from the secretory pathway to other cellular destinations therefore must contain active sorting information in their amino acid sequence or in their structure that is recognized during transit through the cell. We are interested in identifying the sorting information that is present in vacuolar proteins.

The vacuole of $S$. cerevisiae is a lysosomelike organelle in that it contains a number of soluble hydrolytic glycoprotein enzymes $(27,60)$. These include proteinase $A(\operatorname{Pr} A)$, proteinase B (PrB), carboxypeptidase Y (CPY), repressible alkaline phosphatase, and RNase. $\operatorname{Pr} A, \operatorname{PrB}$, and CPY have been shown to be synthesized as inactive proenzyme precursors $(17,29)$. These hydrolases are mannoproteins and initially undergo dolichol-mediated core glycosylation in the ER (18, 62). Subsequently, additional carbohydrate modifications take place in the Golgi complex. Sorting of vacuolar proteins is thought to take place on the trans side of the Golgi complex $(12,21,51)$. The presence of a receptor carrier has not been directly demonstrated for any of the vacuolar proteins, although some evidence suggests that a receptormediated pathway exists $(44,52)$. Just before or upon arrival in the vacuole, the CPY, PrA, and PrB proenzymes are

\footnotetext{
* Corresponding author.
}

processed to their mature forms. Maturation is dependent on a functional $P E P 4$ gene product $(\operatorname{PrA})(19,31)$. The activation of both proPrA and proCPY requires the removal of an amino-terminal propeptide segment $(1,19)$. The regulation of the maturation process is not fully understood, but it may involve a mechanism which is initiated by autocatalysis of proPrA $(31,61)$. The PEP4 gene of yeasts was cloned by complementation in pep4 mutant yeasts $(1,61)$. Sequence analysis indicates that $\operatorname{PrA}$ has extensive homology to aspartyl proteases (61). Initial studies of PrA showed that it contains two N-linked glycosidic side chains (29) and is synthesized as an inactive precursor of 405 amino acids. The signal peptide and propeptide regions make up the $\mathrm{N}$ terminal 76 amino acids of preproPrA. The protein ( $\mathrm{p} 1$ form) undergoes further carbohydrate modification in the Golgi complex to produce a higher-molecular-weight form (p2) with an apparent size of 48,000 to 52,000 daltons $(1,29,61$, 62). Upon delivery to the vacuole, an $\mathrm{N}$-terminal propeptide is cleaved to generate the mature 329 -amino-acid enzyme, which together with its two $\mathrm{N}$-linked oligosaccharide side chains has an apparent molecular weight of 42,000 .

At present little is known about the factors required for delivery of proteins to the vacuole. Unlike the targeting of many mammalian lysosomal enzymes (50), delivery to the vacuole has not been shown to be dependent on a specific glycosyl modification of the protein. In the presence of tunicamycin, a drug that blocks the synthesis of highmannose core oligosaccharides (26), proCPY and alkaline phosphatase are delivered to the vacuole and matured $(7,38$, $48,51)$. This indicates that sorting of proenzymes to the vacuole may occur via direct recognition of an amino acid sequence or conformational feature of the polypeptide. For CPY, it has been shown that a determinant which allows targeting of proCPY to the vacuole resides within the $\mathrm{N}$ terminal propeptide $(21,55)$. Since many of the vacuolar proteases are synthesized as inactive precursors, the propeptide on other vacuolar enzymes also may contain vacuolar sorting information which allows for efficient vacuolar delivery in addition to maintaining the hydrolases in an inactive state before their arrival in the vacuole. The vacuo- 
lar proteins for which sequence information is available do not show any obvious sequence homology. As a result, it has not been feasible to identify vacuolar targeting signals by directly mutating suspected sequences.

As an alternative approach to identifying the vacuolar sorting information in the PEP4 gene product, we constructed fusions of the PEP4 gene to the $S U C 2$ gene (which codes for secreted invertase) of yeasts. We found that the propeptide region of $\operatorname{PrA}$ contains information which is sufficient to divert delivery of the normally secreted enzyme invertase to the vacuole. This indicates that vacuolar targeting information resides within the propeptide of the precursor protein. We also examined proteolytic and glycosyl processing of the wild-type $\operatorname{PrA}$ protein. We found that maturation of preproPrA involves the removal of an $\mathrm{N}$ terminal signal peptide at the level of the ER. The two $\mathrm{N}$-linked core oligosaccharides that are added in the ER are processed and extended with $\alpha-1 \rightarrow 3$-mannose linkages in the Golgi complex. After delivery to the vacuole, the propeptide segment is cleaved to yield the mature, enzymatically active $\operatorname{PrA}$. The half-time for this maturation process is approximately 6 min. In addition, we showed that delivery of PrA to the vacuole is not dependent on glycosyl modification of the protein. Finally, oligonucleotide-directed mutagenesis of the $\operatorname{PrA}$ propeptide revealed that an intact propeptide is critical for maintaining stability of the protein and efficient transit through the secretory pathway.

\section{MATERIALS AND METHODS}

Strains and media. Escherichia coli strains used in this study were MC1061 $\mathrm{F}^{-}$hsdR $h s d M^{+}$araDl39 (araABOICleu) 7679 (lac)X74 galU galK rpsL (6) and JM101 F' traD36 lac $l^{9} \mathrm{Z} \Delta \mathrm{M} 15$ pro $A B \Delta$ (lac-pro) supE thi (33). Yeast strains used were SEY2101 MATa ura3-52 leu2-3,112 suc2- $\Delta 9$ ade2-

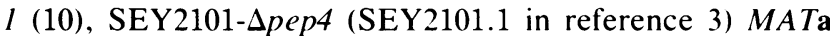
ura3-52 leu2-3,112 suc2- $\Delta 9$ ade2-1 $\Delta p e p 4:: L E U 2$, and SEY2108 MATa ura3-52 leu2-3,II2 suc2- $\Delta 9$ Aprcl::LEU2 (3). Standard methods $(46,49)$ were used to construct yeast strains SEY5187 MATa sec18-1 suc2- 99 leu2-3,112 ura3-52, DKY6182 MATa sec18-I ura3-52 ade2-1 $\Delta p e p 4:: L E U 2$, and

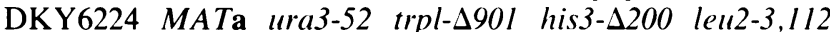
ade2-101 SUC2- $\Delta 9$ Dpep4::LEU2. Strain RDM50-94C MATa sec62-1 leu2-3,112 his4 ura3-52 was supplied by Raymond Deshaies and Randy Schekman.

Standard yeast (49) and E. coli (33) media were used and supplemented as needed. The minimal medium of Wickerham (58) was modified as described previously (21). Bromocresol purple indicator plates were used as described previously $(3,49)$.

Reagents. Zymolyase-100T (Kirin Brewery Co.) was obtained from Seikagako Kogyo Co. (Tokyo, Japan), lyticase was from Enzogenetics, endoglycosidase $\mathrm{H}$ was from $\mathrm{New}$ England Nuclear Corp. (Boston, Mass.), papain was from Worthington Diagnostics (Freehold, N.J.), invertase and CPY were from Boehringer Mannheim Biochemicals (Indianapolis, Ind.), and proteinase $A$ and $\beta$-glucuronidase were from Sigma Chemical Co. (St. Louis, Mo.). DNA restriction and modifying enzymes were from New England BioLabs, Inc. (Beverly, Mass.). $\mathrm{Na}_{2}{ }^{35} \mathrm{SO}_{4}$ was from ICN Pharmaceuticals Inc. (Irvine, Calif.), and Autofluor was from National Diagnostics. All other chemicals were purchased from Sigma. PrB antiserum was a gift from Charles Moehle and Elizabeth Jones, and antiserum to $\alpha-1 \rightarrow 3$-mannose linkages was a gift from Randy Schekman. Fluorescein isothiocyanate-conjugated affinity-purified Fab fragments of antisera directed against rabbit Fab fragments were from Jackson Immunoresearch Laboratories.

Antisera to $\operatorname{PrA}$, CPY, and invertase. To produce antisera to $\mathrm{PrA}, \mathrm{CPY}$, and invertase, commercially purified proteins were deglycosylated with endoglycosidase $\mathrm{H}$ and purified by sodium dodecyl sulfate (SDS)-polyacrylamide gel electrophoresis. Proteins were visualized by Coomassie blue staining, and deglycosylated protein bands were excised from the gel. Homogenized gel slices were mixed with Freund adjuvant and injected (150 $\mu \mathrm{g}$ of protein) into New Zealand White rabbits. Antisera were collected after multiple secondary injections $(75 \mu \mathrm{g})$.

Plasmid constructions. The SUC2 fusion vector pSEYC306 was constructed as described previously (21). The vector pSEYC306 was restricted with the enzymes NruI and PiruI and then ligated to construct the fusion vector pSEYC 308 . This deletion removed an approximately 0.6-kilobase fragment of DNA which includes a $S a l I$ site and maps distal to the $S U C 2$ gene. The pSEYC308 vector then contained a unique $S a l l$ site in the polylinker region $5^{\prime}$ of the $S U C 2$ sequence. Both of these vectors contained sequences that allow for stable maintenance in both $E$. coli (Amp ${ }^{r}$. ColE1 ori) and yeasts (URA3 CEN4 ARS1).

A 4.5-kilobase $B a m \mathrm{HI}$ fragment containing the entire PEP4 gene cloned into the plasmid YEp13 (M80-PEP4) was supplied by Gustav Ammerer. The PEP4-SUC2 gene fusions were constructed as follows. Oligonucleotide-directed mutagenesis was used to insert HindIII restriction sites immediately after the coding sequence for preproPrA amino acids 23. 39, 61, 76, and 90. Bam HI-HindIII fragments derived from the mutated PEP4 genes were then cloned into the BamHI-HindIII sites of pSEYC306 to generate the plasmids pP4I-23, pP4I-39, pP4I-61, pP4I-76, and pP4I-90. The insertion of HindIII sites did not result in any alterations of the $\operatorname{PrA}$ protein sequence of the final fusion constructs. The naturally occurring HindIII site at amino acid 137 was used to construct the plasmid pP4I-137. Oligonucleotide-directed mutagenesis was used to insert a SalI site after amino acid 404 of $\operatorname{PrA}$, and the resulting BamHI-SalI fragment was cloned into the Bam HI-SalI sites of pSEYC308 to construct the plasmid pP4I-404. In this construct, the terminal amino acid of PrA, residue 405, was changed from Ile to Met. For all fusion constructs, the designated name indicates the number of wild-type amino acids from PrA which precede the fusion joint. A single-copy wild-type PEP4 plasmid was constructed by moving a 4.5-kilobase Bam HI-SalI fragment from the plasmid M80-PEP4 into pSEYC306. This plasmid was designated pSEYC306-PEP4. A PEP4 deletion of the coding sequence for amino acid residues 24 to $76(\Delta 24-76)$ was constructed in two steps. The HindIII-AvaI fragment from pSEYC306-PEP4 was ligated into the HindIII-SalI sites of pP4I-23. The resulting construct, $\Delta 24-137$, was digested with HindIII and treated with bacterial alkaline phosphatase. The HindIII fragment from the PEP4 gene which had been mutagenized to insert a HindIII site after amino acid 76 was ligated into the $\Delta 24-137$ construct and screened for the correct orientation. This construct, $\operatorname{PrA} \Delta$ pro, is deleted for amino acids 24 to 76 of preproPrA and contains two amino acid substitutions at positions 77 (Gly to Ala) and 78 (Gly to Cys). The deletion $\Delta 61-76$ was constructed in an analogous manner starting with the plasmid pP4I-61.

Site-specific mutagenesis. Oligonucleotide-directed mutagenesis was performed as described previously $(21,35)$. All mutagenesis was performed on subclones of the appropriate plasmids in M13mp8. Restriction enzyme digestion or DNA 
sequencing or both were used to confirm the presence of mutations in positive plaques (47).

Assays. Invertase assays were done as described previously (11). For filter invertase assays, strains were grown on minimal fructose plates with the appropriate supplements. To test for secreted invertase activity, we replica plated intact colonies onto Whatman no. 1 filter paper which had been presaturated with sucrose and reagents which permit the detection of glucose ( $0.1 \mathrm{M}$ sodium acetate [ $\mathrm{pH}$ 5.1], 0.12 $\mathrm{M}$ sucrose, $0.4 \mathrm{mM} N$-ethylmaleimide, $0.01 \mathrm{mg}$ of horseradish peroxidase per $\mathrm{ml}, 8 \mathrm{U}$ of glucose oxidase per $\mathrm{ml}, 0.6 \mathrm{mg}$ of $O$-dianisidine per $\mathrm{ml}$ ). To score total invertase activity, we permeabilized cells by exposure to chloroform vapor for 5 min before replica plating.

The isolation of purified vacuoles and assays for the marker enzymes $\alpha$-mannosidase, $\alpha$-glucosidase, and NAD PH cytochrome $c$ reductase were performed as described previously $(3,14,25,39)$.

Immunofluorescence microscopy. Fab fragments were prepared from an immunoglobulin $\mathrm{G}$ fraction of $\operatorname{Pr} \mathrm{A}$ antiserum as described previously (28). Cells (15 ml) were prepared and stained as described before (8), using a 1:30 dilution of anti-PrA Fab fragments and a 1:50 dilution of fluorescein isothiocyanate-conjugated Fab fragments (goat) directed against Fab fragments of rabbit immunoglobulin G. Cells were viewed with a Zeiss microscope with epifluorescence and Nomarski optics.

Immunoprecipitation. Cells were grown to the mid-logarithmic phase in Wickerham minimal proline medium plus $0.1 \mathrm{mM} \mathrm{MgSO}_{4}$. Two units of cells at an optical density at $600 \mathrm{~nm}$ of 1.0 were centrifuged, washed twice with water, and suspended in $0.25 \mathrm{ml}$ of the above medium lacking $\mathrm{MgSO}_{4}$. After incubation for 30 to $60 \mathrm{~min}$ at the appropriate temperature, bovine serum albumin (final concentration 2 $\mathrm{mg} / \mathrm{ml}$ ) and $250 \mu \mathrm{Ci}$ of carrier-free $\mathrm{Na}_{2}{ }^{35} \mathrm{SO}_{4}$ were added. Cells were incubated for 5 to $10 \mathrm{~min}$, and the chase was initiated by the addition of $\mathrm{MgSO}_{4}$ to $50 \mathrm{mM}$ final concentration. The chase was terminated by the addition of trichloroacetic acid (TCA) to 5\% final concentration. Precipitates were collected by centrifugation in a microcentrifuge and washed twice with acetone. Dried pellets were suspended in $50 \mu \mathrm{l}$ of resuspension buffer $(50 \mathrm{mM}$ Tris hydrochloride [pH 7.5], $1 \mathrm{mM}$ EDTA, 1\% SDS). Cells were lysed in the presence of glass beads $(0.5 \mathrm{~mm})$ with a Scientific Products vortex mixer ( $1 \mathrm{~min}$ ) followed by boiling for $4 \mathrm{~min}$. The lysate was diluted by the addition of $1 \mathrm{ml}$ of IP buffer (0.5\% Tween 20, $50 \mathrm{mM}$ Tris hydrochloride ( $\mathrm{pH} 7.5), 150$ $\mathrm{mM} \mathrm{NaCl}, 0.1 \mathrm{mM}$ EDTA), centrifuged, and transferred to a new tube. Antisera ( 1 to $10 \mu \mathrm{l})$ and bovine serum albumin ( 2 $\mathrm{mg} / \mathrm{ml}$, final concentration) were added, and the samples were gently agitated at $4^{\circ} \mathrm{C}$ for $2 \mathrm{~h}$. Immunoprecipitates were collected by the addition of 50 to $75 \mu \mathrm{l}$ of a $3.6 \%(\mathrm{wt} / \mathrm{vol})$ suspension of protein A-Sepharose CL-4B beads followed by gentle agitation at $4^{\circ} \mathrm{C}(1 \mathrm{~h})$. The beads were collected by centrifugation in a microcentrifuge for $1 \mathrm{~min}$. The beads then were washed twice with IP buffer and once with $1 \% \beta$ mercaptoethanol. Resuspension buffer was added (50 $\mu \mathrm{l})$, followed by boiling for $4 \mathrm{~min}$. The released antigen was diluted with $1 \mathrm{ml}$ of IP buffer, and a second immunoprecipitation was performed. The final pellet was suspended in $\mathbf{3 0}$ $\mu \mathrm{l}$ of $2 \times$ SDS sample buffer and boiled $4 \mathrm{~min}$. Samples (20 $\mu l)$ were loaded onto a $9 \%$ polyacrylamide-SDS gel. After electrophoresis, gels were fixed and treated with Autofluor.

\section{RESULTS}

PEP4-SUC2 gene fusions. The SUC2 gene product, invertase, is an easily assayable glycoprotein enzyme which is competent for delivery through the secretory pathway $(5$, 12). Invertase normally resides in the yeast periplasm where it catalyzes the hydrolysis of extracellular sucrose, the first step in sucrose metabolism. Together, these properties make invertase a useful biochemical marker enzyme in gene fusion studies when analyzing protein sorting through the yeast secretory pathway. Plasmid vectors that permit the construction of gene fusions to $S U C 2$ have been described (10, 21; Materials and Methods). We used these vectors to construct seven PEP4-SUC2 gene fusions containing different-sized amino-terminal coding segments from the PEP4 gene fused to a constant fragment of the $S U C 2$ gene (Fig. 1). Each of these gene fusions directed the synthesis of PrAinvertase hybrid proteins that exhibited invertase activity in yeasts (Fig. 2 and 3). The apparent molecular weight of each of the hybrid proteins synthesized in the presence of tunicamycin was consistent with that expected from the deduced amino acid sequence of each of the PEP4-SUC2 hybrid gene constructs (Fig. 2). The unglycosylated hybrid proteins ranged in size from approximately 60,000 to 100,000 daltons. This analysis of the hybrid proteins as well as quantitative invertase assays indicated that each of the gene fusions directed the synthesis of similar levels of hybrid protein (Fig. 3).

Localization of hybrid proteins. The invertase activity associated with each of the hybrid proteins served as a convenient marker to detect the cellular location of these hybrid proteins. Since sucrose is unable to cross the plasma membrane, the growth phenotype of a strain utilizing sucrose as its sole fermentable carbon source provides an indication as to the cellular distribution of the invertase activity of that strain. The parental strain SEY 2108 is deleted for the chromosomal $S U C$ loci and therefore is unable to utilize sucrose as a carbon source. Because this strain lacks endogenous invertase, any invertase activity detected in the strain when it is harboring the different PEP4-SUC2 gene fusions must be due to expression from the gene fusions. Strains expressing fusion proteins with 23,39 , or 61 amino acids of preproPrA fused to a functional invertase protein had Suc ${ }^{+}$phenotypes, indicating that a significant amount of the hybrid protein was secreted from these cells. In contrast, when PEP4-SUC2 fusions containing the coding information for 90,137 , or 404 amino acids of preproPrA were analyzed in this way, the cells showed a Suc ${ }^{-}$phenotype, indicating that these hybrid proteins were being retained within the cell. The PrA-Inv76 fusion (N-terminal 76 amino acids of preproPrA fused to invertase) had an intermediate growth phenotype on sucrose. Cells with this fusion grew on sucrose but did so much more slowly than those harboring shorter PEP4-SUC2 gene fusions. Growth on sucrose was very sensitive to even small amounts of invertase enzyme activity at the cell surface, but this assay was limited to assessing only the steady-state level of secreted hybrid protein. The poor growth of cells with the PrA-Inv76 fusion on sucrose plates indicated a low level of secretion of this hybrid protein.

A steady-state analysis of hybrid protein secretion was also done with filter invertase assays of intact and chloroform-permeabilized cells (Fig. 3). Strain SEY2108 harboring each of the different PEP4-SUC2 gene fusions was patched onto a minimal fructose master plate. After incubation at $30^{\circ} \mathrm{C}$, filter invertase assays were performed as described in 

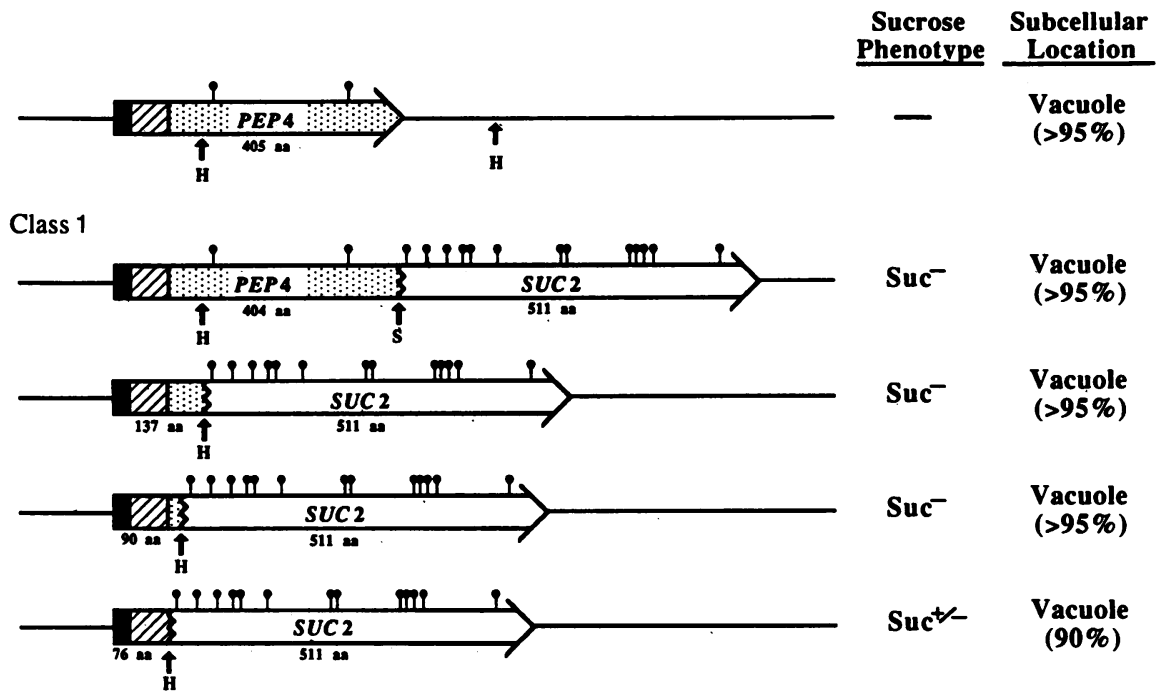

Class 2

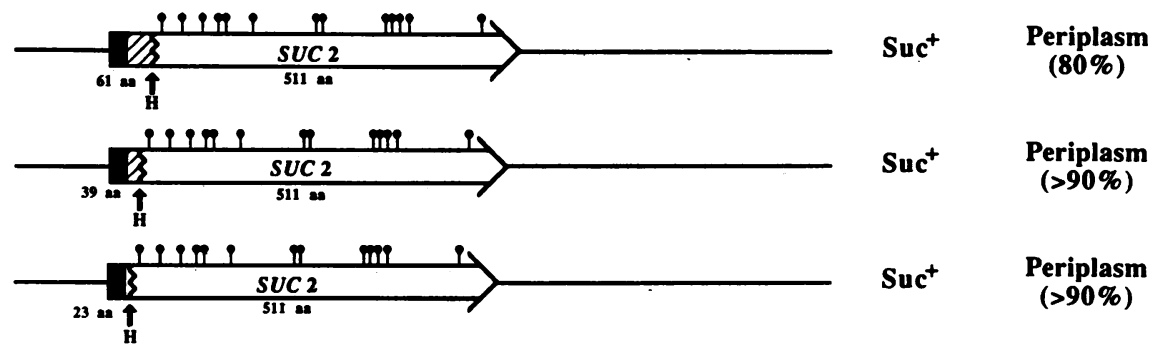

FIG. 1. PEP4-SUC2 gene fusions. Two classes of PEP4-SUC2 gene fusions are shown. The PEP4 gene is divided into the coding regions for the presumed signal peptide (solid box), the propeptide (hatched box), and the mature PrA enzyme (stippled box). The SUC2 gene is indicated by the open box. The approximate positions of the two asparagine-linked core oligasaccharides as determined from the amino acid sequence of the PrA protein $(1,61)$ and the 13 potential sites for core oligosaccharide addition on invertase are indicated above the PEP4 and $S U C 2$ genes, respectively. The growth phenotype on sucrose of a yeast strain deleted for its normal SUC loci and harboring each of the indicated gene constructs on a low-copy (CEN4-ARSI) yeast plasmid vector is shown. Cofractionation of the PEP4 gene product and the hybrid protein products of each of the PEP4-SUC2 gene fusions with isolated vacuoles is as indicated. aa, Amino acids; H, HindIII; S, SalI.

Materials and Methods. Assays with intact cells detected only the invertase activity that was associated with hybrid proteins which were secreted from the cell. Permeabilization of the cells by exposure to chloroform vapor enables the detection of internal invertase activity in addition to any which has been secreted. The parental strain SEY2108 (P) is deleted for its chromosomal SUC loci and served as a negative control (Fig. 3). Strains expressing the PrA-Inv23, -39 , or -61 hybrid proteins tested strongly positive for invertase activity when intact cells were assayed, indicating secretion of substantial amounts of the hybrid proteins (Fig. $3)$. In contrast, the PrA-Inv76 fusion only gave a very weak signal when intact cells were examined. This is similar to the result seen with growth phenotypes on sucrose indicator plates and suggests that this hybrid protein is mostly retained within the cell. The PrA-Inv fusions with 90, 137, or 404 amino acids of preproPrA were negative for secreted invertase activity as determined by the filter assay. All the fusions expressed levels of total invertase activity similar to those seen with the chloroform-permeabilized cells. Differences in secretion of the hybrid proteins, then, are not the result of differences in their level of expression.

Invertase enzyme assays were performed on intact as well as detergent-permeabilized yeast cells to quantitate more carefully the amount of the hybrid proteins that is secreted. Invertase assays with detergent-lysed cells permit a measure

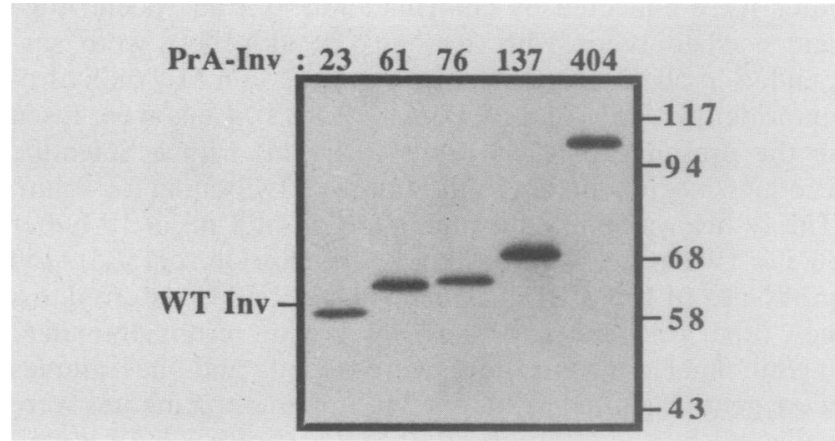

FIG. 2. Immunoprecipitation of unglycosylated PrA-Inv hybrid proteins. Immunoprecipitations of strain SEY2101- -pep4 expressing the indicated hybrid proteins were done as described in Materials and Methods with the following modifications. Tunicamycin (final concentration of $20 \mu \mathrm{g} / \mathrm{ml}$ ) was added to inhibit glycosylation $15 \mathrm{~min}$ before the addition of $\mathrm{Na}_{2}{ }^{35} \mathrm{SO}_{4}$. Labeling was allowed to continue for $5 \mathrm{~min}$ followed by a 15-min chase. Invertase antiserum was used to precipitate the hybrid proteins. Radiolabeled proteins were analyzed by SDS-polyacrylamide gel electrophoresis and autoradiography. The number of amino acids of preproPrA fused to invertase is indicated above each lane. The position of protein standards (molecular weight $\times 10^{3}$ ) and the migration position of unglycosylated wild-type invertase (WT Inv) are indicated. 


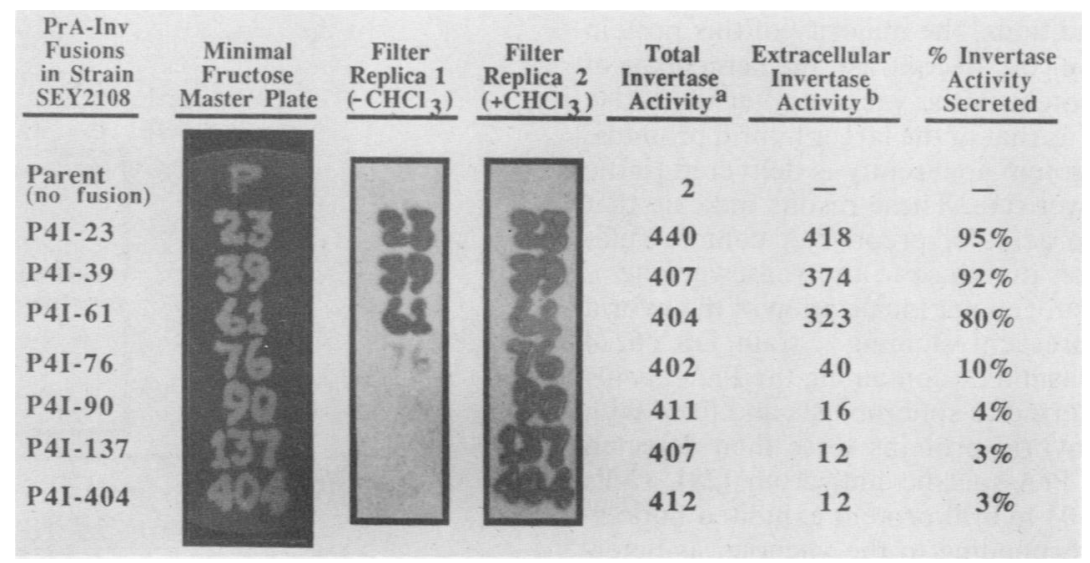

FIG. 3. Cellular distribution of preproPrA-Inv hybrid proteins. Strain SEY2108 harboring the indicated PEP4-SUC2 fusion plasmids was inoculated onto a minimal fructose master plate in patterns denoting the number of amino acids of preproPrA that was fused to invertase in each case. Invertase filter assays were performed as described in Materials and Methods, using filter replicas of the master plate before (filter 1) and after (filter 2) chloroform vapor permeabilization of the yeast cells. Quantitative liquid invertase assays were done on the same strains grown in yeast nitrogen base minimal medium (Difco Laboratories) supplemented with $2 \%$ glucose. Invertase activity is expressed as nanomoles of glucose released per minute per unit of cells at an optical density of $600 \mathrm{~nm}$. The percent secreted invertase activity was calculated by subtracting the background (SEY2108, no fusion plasmid) and then calculating (extracellular activity/total activity) $\times 100$.

of the total cellular enzyme activity. Since yeast cells do not transport the invertase substrate, sucrose, across the plasma membrane, enzyme assays with whole yeast cells (as in the filter assay) detect only the invertase activity that has been secreted from the cell (37). The PEP4-SUC2 fusions could be grouped into two classes based on the location of the invertase activity associated with the hybrid proteins. The class 1 fusions (containing 76 or more amino acids of preproPrA) represented those for which the majority of the invertase activity $(>90 \%)$ remained within the cell (Fig. 1 and 3). It should be noted that the PrA-Inv76 fusion contains the entire $\operatorname{PrA}$ signal sequence and propeptide region but none of the mature polypeptide. In contrast, PEP4-SUC2 gene fusions expressing hybrid proteins that contained 23 . 39 , or 61 amino acids of preproPrA (class 2) secreted 65 to $95 \%$ of the hybrid proteins from the cell as determined by the invertase assays. This activity was primarily localized to the periplasm.

To determine more accurately the location of the invertase activity, we fractionated cells containing the various hybrid proteins on discontinuous Ficoll step-density gradients (3). The isolated fractions were assayed along with the crude cell extract for the following enzyme activities: $\alpha$-mannosidase (vacuole membrane marker), invertase (hybrid protein), NADPH cytochrome $c$ reductase (ER membrane marker), and $\alpha$-glucosidase (cytoplasmic marker). The percent recovery of each of these enzyme activities in the vacuoleenriched fraction is indicated in Fig. 4. Based on both protein and marker enzyme recoveries, this fractionation procedure gives an approximately 50 -fold purification of vacuolar enzymes (22). In all cases, 30 to $40 \%$ of the $\alpha$-mannosidase activity was recovered in the vacuole-enriched fraction compared with 4 to $6 \%$ of the NADPH cytochrome $c$ reductase and 1 to $2 \%$ of the $\alpha$-glucosidase. The invertase activity derived from the $\operatorname{PrA}-\operatorname{Inv} 23$ and PrA-Inv39 fusions did not cofractionate with the $\alpha$-mannosidase activity. This was expected since these proteins were secreted from the cell (Fig. 3). Fusions of 90, 137, or 404 amino acids showed nearly quantitative cofractionation of the invertase and $\alpha$-mannosidase activities, indicating that these hybrid proteins are efficiently targeted to the vacuole. The PrA-Inv61 and PrA-Inv76 hybrid proteins resulted in approximately 10 and $65 \%$, respectively, of the invertase activity being targeted to the vacuole. When vacuoles were isolated after a 1-h chase in the presence of cycloheximide $(100 \mu \mathrm{g} / \mathrm{ml}$, final concentration), the PrA-Inv61 and PrAInv76 hybrid proteins showed approximately 20 and $90 \%$, respectively, of the invertase activity (after correcting for recoveries) in the vacuole (data not shown). While there was an increase in the level of the PrA-Inv61 hybrid protein in the

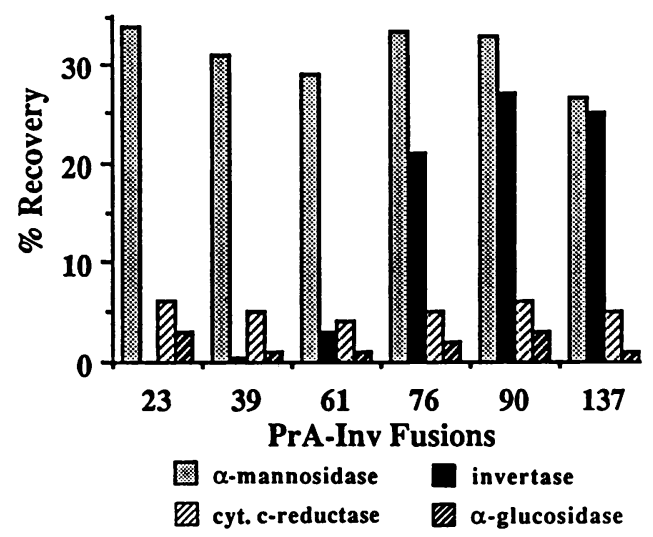

FIG. 4. Vacuole fractionation data for PrA-Inv hybrid proteins Yeast strain SEY2108 harboring the indicated PrA-Inv fusion vectors was subjected to enzymatic digestion of the cell wall followed by mild lysis in the presence of DEAE-dextran. The resulting crude extract was fractionated on a discontinuous Ficoll step gradient. The crude extract and the gradient fraction enriched for intact vacuoles were assayed to determine the percent recovery of $\alpha$-mannosidase (vacuole membrane), invertase (PrA-invertase), $\alpha$-glucosidase (cytoplasm), and NADPH cytochrome $c$ reductase (ER). The percent recovery for each of these enzymes was determined by dividing the total enzyme activity recovered in the vacuole-enriched fraction by the total activity loaded on the gradient. The invertase activity associated with the PrA-Inv76 hybrid protein showed approximately $65 \%$ cofractionation with $\alpha$-mannosidase activity as presented in the figure. This hybrid protein showed approximately $90 \%$ cofractionation when cycloheximide $(100 \mu \mathrm{g} / \mathrm{ml}$, final concentration) was added $1 \mathrm{~h}$ before harvesting the cells (see text). Results for PrA-Inv404 are not shown but were essentially the same as those shown for PrA-Inv137. 
vacuole under these conditions, the majority of this protein was still secreted from the cell. In contrast, the percentage of the PrA-Inv76 hybrid protein in the vacuole after the chase was essentially the same as that of the larger hybrid proteins. The PrA-Inv76 hybrid protein apparently is delivered to the vacuole at a slightly slower rate. These results indicate that the N-terminal 76 amino acids of preproPrA contain sufficient information to direct invertase to the yeast vacuole.

We also analyzed the subcellular localization of the hybrid proteins by immunofluorescent staining. Strain DKY6224 ( $\Delta$ pep4) containing no plasmid or containing the PrA-Inv404 fusion plasmid was converted to spheroplasts and fixed with formaldehyde (8). The hybrid proteins were then detected with Fab fragments of PrA-specific antiserum (28). Cells expressing the PrA-Inv404 hybrid protein exhibited fluorescence in the region corresponding to the vacuole, as determined by Nomarski optics (Fig. 5). Although not all the cells showed the same intensity of fluorescent staining, in every case the fluorescence was associated with the vacuole. This confirms the results obtained with the fractionation data, which indicated that the PrA-Inv404 hybrid protein is localized to the vacuole.

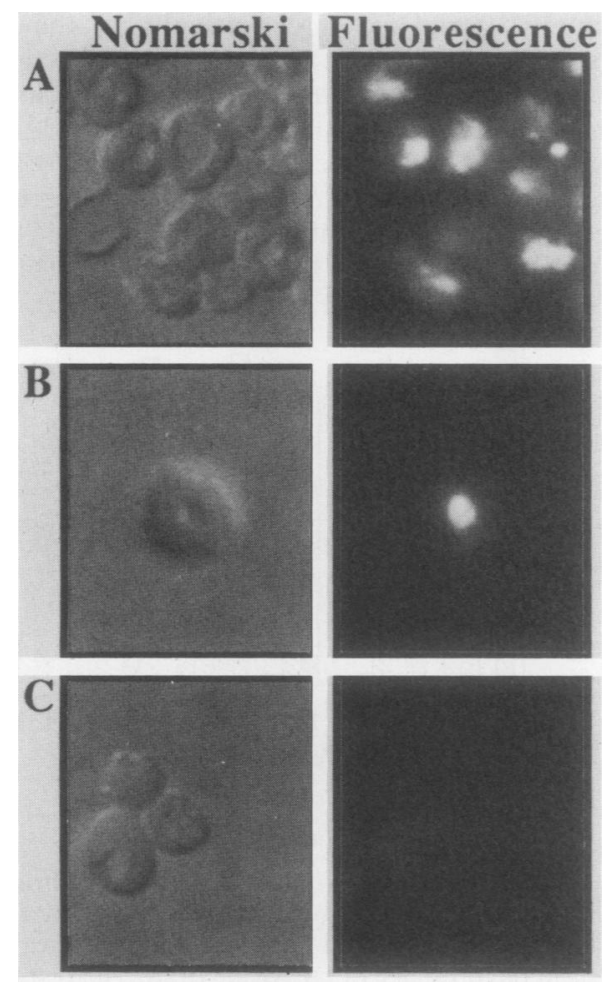

FIG. 5. Immunofluorescence detection of hybrid proteins. Strain DKY6224 without a plasmid or with the PrA-Inv404 fusion plasmid was subjected to limited enzymatic digestion of the cell wall and fixed in formaldehyde. Cells were stained with Fab fragments from PrA-specific antiserum and fluorescein isothiocyanate-conjugated second antibody as described in Materials and Methods. Cells were examined by Nomarski optics and fluorescence microscopy as indicated. The vacuoles correspond to the indentations within the cells when viewed by Nomarski optics. The identification of the vacuole was confirmed by immunofluorescence detection of wildtype CPY by using Fab fragments from CPY-specific antisera and by staining nonfixed cells with lucifer yellow, fluorescein isothiocyanate, and quinacrine $(41,43,57$; data not shown). (A and B) Strain DKY6224 ( $\Delta$ pep4) expressing the PrA-Inv404 hybrid protein. (C) Strain DKY6224 ( $\Delta p e p 4)$ without a plasmid. Magnification, $\times 300$.

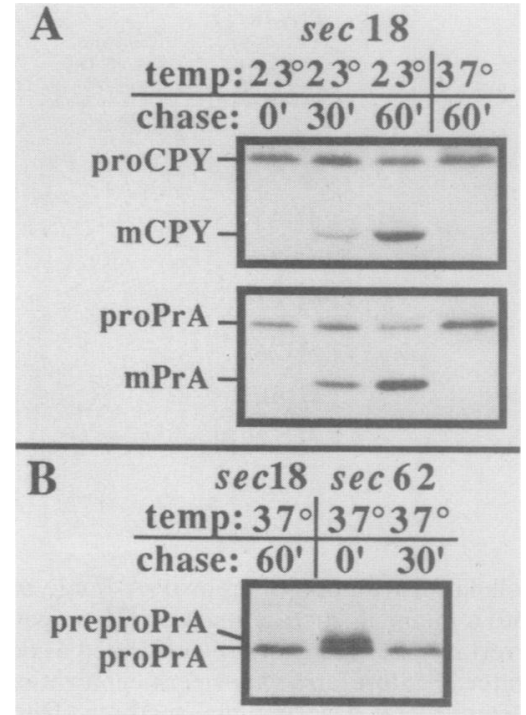

FIG. 6. Processing of wild-type PrA in sec mutant yeasts. Temperature-sensitive sec18 (SEY5187) (A) or sec18 and sec62 (RDM5094C) mutant strains (B) were grown to the mid-log phase at $23^{\circ} \mathrm{C}$. Tunicamycin was added (final concentration, $20 \mu \mathrm{g} / \mathrm{ml}$ ), and the cultures were shifted to $37^{\circ} \mathrm{C}$ for $20 \mathrm{~min}$ as indicated. Both strains were labeled for $10 \mathrm{~min}$, and the chase was then initiated by the addition of $50 \mathrm{mM} \mathrm{MgSO}_{4}$. The chase was stopped at the indicated times by the addition of TCA. Double immunoprecipitations were done with CPY and PrA antisera as described in Materials and Methods. The predicted locations for unglycosylated precursor and mature CPY and PrA proteins are indicated.

Processing of PrA. Our gene fusion results indicated that the 76-amino-acid prepropeptide sequence of $\operatorname{PrA}$ contains at least two protein-sorting signals: a signal which allows translocation across the ER membrane and a signal that directs subsequent sorting to the vacuole. The efficient secretion of the PrA-Inv23 hybrid protein indicated that the $\mathrm{N}$-terminal 23 amino acids of preproPrA are able to functionally replace the normal 19-amino-acid signal peptide of invertase which is deleted from all the gene fusion constructs and is essential for ER targeting and translocation of wildtype invertase $(22,40)$. This hybrid protein, however, lacked sufficient information for vacuolar sorting. Therefore, additional sequences distal to the signal sequence must be required to direct efficient delivery to the vacuole. It is possible that the $\mathrm{N}$-terminal signal peptide not only directs ER targeting but also directly contributes to the final targeting of PrA to the vacuole. Sequences which are involved in vacuolar targeting would presumably have to remain associated with the protein until sorting takes place, and data suggest that sorting of vacuolar proteins occurs in the Golgi complex $(21,51)$. To analyze the compartmental organization of PrA maturation, we used the yeast sec mutants. A signal sequence cleavage site is predicted to be present between amino acids 22 and 23 of preproPrA based on the rules of von Heijne (56). To determine whether the preproPrA signal peptide is cleaved, we analyzed PrA processing in the temperature-sensitive yeast secretory mutants with mutations in SEC62 and SEC18. sec62 cells are defective in protein translocation across the ER membrane (9), and sec18 cells are blocked in protein transit out of the ER at the nonpermissive temperature (36). Both strains were labeled in the presence of tunicamycin to block Asn-linked carbohydrate addition. This permits direct comparison between the 
unglycosylated ER-translocated (secl8) and nontranslocated (sec62) PrA proteins. The sec62 mutation does not cause a complete block in ER translocation (9), and both preproPrA and proPrA could be seen after pulse-labeling for $10 \mathrm{~min}$ (Fig. 6). Comparison of the $\operatorname{PrA}$ protein immunoprecipitated from the sec62 and sec 18 strains labeled at the nonpermissive temperature indicated that the signal peptide on the wild-type $\operatorname{PrA}$ protein is cleaved from preproPrA and that this cleavage occurs in the ER (Fig. 6).

A similar analysis was done to determine whether the signal peptide was removed from the PrA-Inv hybrid proteins. The shortest PrA-Inv fusion contains the $\mathrm{N}$-terminal 23 amino acids of preproPrA. The secretion of this hybrid protein from the cell (Fig. 3) indicated the presence of a functional signal sequence. The PrA-Inv23 hybrid protein immunoprecipitated from a sec18 strain labeled in the presence of tunicamycin at the nonpermissive temperature comigrated with normally processed $S U C 2$-encoded invertase and not with unprocessed invertase (data not shown). This indicated that a signal peptide cleavage site maps within the $\mathrm{N}$-terminal 23 amino acids of preproPrA, consistent with the predicted location for such a site. Molecular weight determinations on other fusion proteins indicated that the signal peptide is cleaved from each of the hybrid proteins. In both wild-type and hybrid proteins then, the $\operatorname{PrA}$ signal peptide apparently is cleaved at the level of the ER.

Our mapping studies of the preproPrA vacuolar sorting signal are consistent with previous observations made with vacuolar CPY $(21,55)$. Both preproPrA and preproCPY contain vacuolar sorting information in their propeptide sequences. No obvious sequence homology is observed, however, when comparing the propeptide of proPrA with that of proCPY. One explanation for this would be that PrA and CPY sort to the vacuole by independent mechanisms. If independent pathways are utilized, they may be reflected in different rates for maturation of proPrA and proCPY. To address this question, we carefully analyzed the processing kinetics of the intact wild-type $\operatorname{PrA}$ and CPY proteins. Pulse-chase labeling of yeast cells followed by immunoprecipitation with antisera directed against PrA and CPY showed a half-time of approximately $6 \mathrm{~min}$ for the processing of proPrA to the mature enzyme (Fig. 7). This paralleled almost exactly the observed rate for maturation of proCPY and is consistent with previously reported processing kinetics for CPY $(16,17)$.

In addition, we determined whether glycosyl modification of $\operatorname{PrA}$ was required for the sorting of this enzyme to the vacuole, a requirement not observed with CPY (48). Yeast cells were labeled with $\mathrm{Na}_{2}{ }^{35} \mathrm{SO}_{4}$ for $10 \mathrm{~min}$ in the presence of tunicamycin. During a chase period, $\operatorname{PrA}$ was converted to a stable protein that migrated as expected for unglycosylated mature $\operatorname{PrA}$, indicating arrival in the vacuole (Fig. 6). The rate of processing of PrA occurred with kinetics which were similar to those observed for CPY (Fig. 6). This indicates that targeting of $\operatorname{PrA}$ to the vacuole as well as processing to the mature form (29) are not dependent on carbohydrate addition. This agrees with our observation that PrA-Inv fusions containing 76 to 137 amino acids of $\operatorname{PrA}$, while lacking sites for core oligosaccharide addition on the PrA portion of the protein, are competent for efficient targeting to the vacuole.

Deletions in PrA. To confirm the role of the amino-terminal portion of proPrA in directing the vacuolar localization of $\operatorname{PrA}$ and to define more precisely the location of the targeting signal within the propeptide region, we constructed internal deletions in the propeptide segment of the wild-type $\operatorname{PrA}$ protein. Initially, we deleted the coding sequence for the entire propeptide segment (amino acids 24 to 76). This deletion construct, $\operatorname{Pr} A \Delta$ pro $(\Delta 24-76)$, was introduced into yeast strain SEY2101- $\Delta p e p 4$, which is deleted for the genomic copy of the PEP4 gene. A pulse-chase analysis was utilized to follow the transit of the $\operatorname{Pr} A \Delta$ pro polypeptide. We found that deletion of the entire prosequence resulted in degradation of approximately $95 \%$ of the protein during a 90-min chase period (Fig. 7). To determine whether this degradation occurs in the ER, we used the sec18 mutant yeast strain DKY6182, deleted for the chromosomal PEP4 locus, to analyze the stability of the $\operatorname{PrA} \Delta$ pro protein. $\operatorname{PrA} \Delta$ pro immunoprecipitated from strain DKY6182 at the nonpermissive temperature appeared to be stable during a 2-h chase. Degradation of this protein, then, may not occur in the ER, or at least not before the secl8 block. Interestingly, the small amount of $\operatorname{PrA} \Delta$ pro which was stable $(<5 \%)$ in strain SEY2101- $\Delta$ pep4 underwent conversion to a highermolecular-weight form that comigrated with wild-type mature PrA (Fig. 7). We believe this represents conversion of the $\operatorname{Pr} A \Delta$ pro protein from a $\mathrm{p} 1$ to a $\mathrm{p} 2$ form corresponding to a Golgi-specific glycosyl modification of the deleted protein. To further analyze the transit of $\operatorname{Pr} A \Delta$ pro, the protein present after 5 and 90 min of chase was first immunoprecipitated with $\operatorname{PrA}$-specific antiserum, followed by a second immunoprecipitation with antiserum that specifically recognizes $\alpha-1 \rightarrow 3$-mannose linkages that are added to core oligosaccharides in the Golgi complex $(2,15)$. Accordingly, p2 and mature forms of CPY and PrA but not the p1 form should be recognized by this antiserum. As expected, when

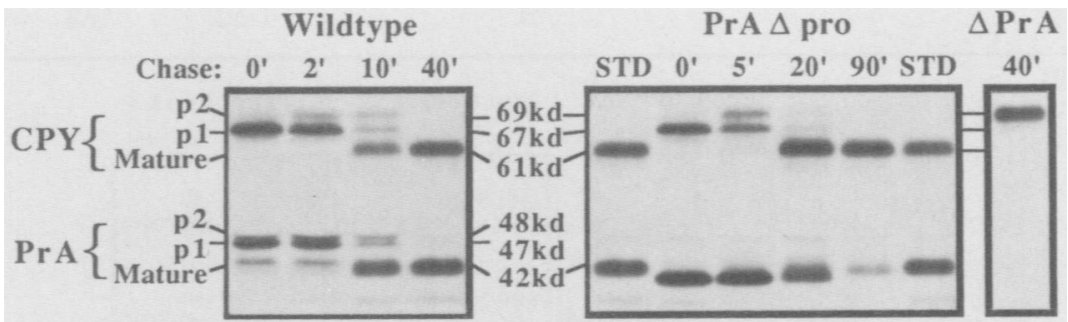

FIG. 7. Processing kinetics of wild-type PrA and PrA deleted for amino acids 24 to $76(\operatorname{PrA} \Delta$ pro). Strain SEY2101- $\Delta$ pep4 containing no plasmid $(\triangle \operatorname{PrA})$ or containing plasmids which express wild-type $\operatorname{PrA}$ or $\operatorname{PrA} \Delta$ pro was labeled at $30^{\circ} \mathrm{C}$ for 5 min and chased for the indicated times (', minutes). Additional time points were taken for wild-type PrA to allow a more accurate determination of the half-time for processing (data not shown). Double immunoprecipitations were performed with CPY and PrA antiserum. Lanes designated as standards (STD) are equivalent to the 40-min chase point in the wild-type control experiment and mark the position of mature CPY and PrA. The approximate molecular sizes of the different forms of CPY and PrA are indicated (kd, kilodaltons). The band seen at the 0- and 2-min time points that migrates at a position on the gel slightly above mature PrA is presumably unglycosylated preproPrA. The disappearance of this band during the chase can clearly be seen when additional time points are analyzed. 


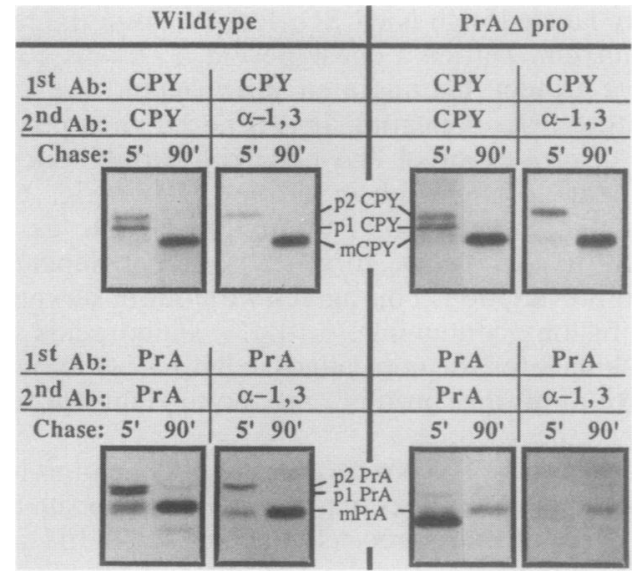

FIG. 8. Immunoprecipitation of CPY, PrA, and PrA $\Delta$ pro with $\alpha-1 \rightarrow 3$-mannose-specific antiserum. Samples were prepared as described in the legend to Fig. 7. The first immunoprecipitations were done with CPY or PrA antiserum as indicated. A second immunoprecipitation was done with CPY, $\operatorname{PrA}$, or $\alpha-1 \rightarrow 3$-mannose antiserum as indicated. Ab, Antibody; ', minutes.

cells were labeled for $5 \mathrm{~min}$ followed by a 5 -min chase, all the p2 and mature PrA and CPY were immunoprecipitated with the $\alpha-1 \rightarrow 3-$ mannose-specific antiserum, indicating that these forms of the proteins were modified by the Golgi-specific $\alpha-1 \rightarrow 3$-mannosyl transferase (Fig. 8). When $\operatorname{PrA} \Delta$ pro was analyzed with the $\alpha-1 \rightarrow 3$-mannose-specific antiserum, the large amount of protein which was present after $5 \mathrm{~min}$ of chase was not immunoprecipitated. In contrast, the small amount of $\operatorname{PrA} \Delta$ pro which was stable after a 90 -min chase was precipitated under the same conditions. At least some fraction of this deleted protein appeared to undergo glycosyl processing in the Golgi complex. However, this processing was much slower than that seen for the wild-type preproPrA protein; it took approximately 10 times longer to process $\operatorname{PrA} \Delta$ pro compared with wild-type preproPrA. The instability of the $\operatorname{PrA} \Delta$ pro mutant protein has thus far prevented us from directly determining the cellular location of this protein by cell fractionation. Indirect evidence suggests, however, that at least some fraction of the $\mathrm{p} 2$ form of $\operatorname{PrA} \Delta$ pro is delivered to the vacuole. Maturation of proCPY is dependent on an active PEP4 gene product $(27,60)$. Strain SEY2101-Apep4, which is deleted for the chromosomal PEP4 locus, accumulated CPY as the $\mathrm{p} 2$ form in the vacuole, indicating the requirement for a functional PrA enzyme in the maturation of this protein (Fig. 7). When this strain, which lacks wild-type $\operatorname{PrA}$, expressed the $\operatorname{Pr} A \Delta$ pro protein, proCPY was processed to the mature enzyme with normal kinetics (Fig. 7). Importantly, analysis of CPY processing in a sec 18 mutant strain suggests that the maturation of CPY, which is dependent on $\operatorname{Pr} A$ or $\operatorname{PrA\Delta } \Delta$ pro, cannot occur in the ER (data not shown). This may be due to a requirement for the lower $\mathrm{pH}$ of the vacuole or for additional vacuolar components for $\operatorname{PrA}$ activity $(31,61)$. This observation, along with the kinetics of CPY processing, suggests that at least some of the small amount of stable $\operatorname{Pr} A \Delta$ pro is targeted to the vacuole.

The instability of the $\operatorname{Pr} A \Delta$ pro protein may result from the extensive nature of the $\Delta 24-76$ deletion. To avoid this protential problem, we constructed two smaller deletions in the PrA propeptide; one removed the coding sequence for amino acids 23 to 39 and the second deleted amino acids 61 to 76 of preproPrA. Based on the results from the fusion proteins, the $\Delta 23-39$ mutation was expected to remove information that was not part of the preproPrA vacuolar sorting signal, while the $\Delta 61-76$ mutation was expected to inactivate the vacuolar targeting signal. Surprisingly, we found that each of these deletion constructs directed the synthesis of unstable polypeptides, as was observed with the PrA $\Delta$ pro mutant. Less than $10 \%$ of these mutated proteins were present after a 5-min labeling and 60-min chase, similar to the result for $\operatorname{Pr} A \Delta$ pro. In both cases, however, the small amount of immunoprecipitable protein which was stable appeared to migrate on an SDS gel at the position of mature $\operatorname{PrA}$, suggesting that the remaining propeptide was removed (data not shown). In addition, CPY was processed with normal kinetics.

The instability of each of the mutant preproPrA proteins indicated that the wild-type propeptide may influence the folding and final structure of $\operatorname{PrA}$. Deletions in the propeptide may prevent the mutated proteins from attaining the native protease-resistant conformation. This aberrant folding also appears to interfere with transit of proPrA from the

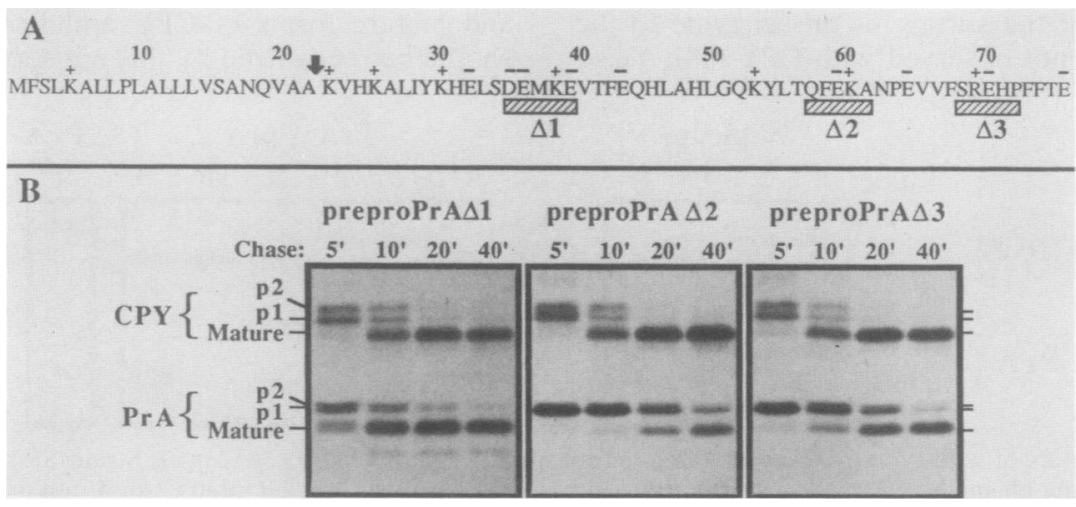

FIG. 9. Deletions in the propeptide affect the kinetics of PrA delivery to the vacuole. (A) Amino acid sequence of the PrA prepropeptide. The arrow above the sequence indicates the predicted site for signal peptide cleavage. The regions which have been deleted individually in the constructs preproPrA $\Delta 1,-\Delta 2$, and $-\Delta 3$ are as indicated. (B) Strain SEY2101- $\Delta$ pep4 expressing the indicated preproPrA constructs was labeled at $30^{\circ} \mathrm{C}$ for $5 \mathrm{~min}$ with $\mathrm{Na}_{2}{ }^{35} \mathrm{SO}_{4}$. Chase was initiated by the addition of $\mathrm{MgSO}_{4}(50 \mathrm{mM}$ final concentration), and samples were TCA precipitated at the indicated time points. Double immunoprecipitations were done with CPY and PrA antiserum. The positions of the different processed forms of the proteins are indicated. ', minutes. 
ER to the Golgi complex. This early sorting-transit defect prevented us from analyzing the subsequent vacuolar sorting decision in the Golgi complex. In a final attempt to overcome the instability problem, we constructed a set of three deletions that removed the coding information for only five amino acids each (Fig. 9). These proteins were designated preproPrA $\Delta 1$ (deleted for amino acids 36 to 40 ), $-\Delta 2$ (amino acids 57 to 61 deleted) and $-\Delta 3$ (amino acids 68 to 72 deleted). Proteins with these deletions did not show the instability seen with larger deletions (Fig. 9). The processing kinetics of these proteins were analyzed by pulse-labeling cells harboring these constructs and immunoprecipitating at various points during a chase period (Fig. 9). PreproPrA $\Delta 1$ showed maturation kinetics which were indistinguishable from those of the wild-type protein (Fig. 9). Based on our results with the PEP4-SUC2 fusions, this deletion was predicted to be located outside the region containing vacuolar sorting information. Both preproPrA $\Delta 2$ and $-\Delta 3$ showed significant kinetic delays in processing of $\operatorname{Pr} A$ from the $\mathrm{p} 1$ to the $\mathrm{p} 2$ form, although both constructs were delivered to the vacuole as evidenced by the processing of the $\mathrm{p} 2$ form to the mature enzyme (Fig. 9). These two proteins had alterations in the propeptide which were more distal to the $\mathrm{NH}_{2}$ terminus than preproPrA $\Delta 1$ and showed a two- to fourfold delay in conversion of preproPrA to the mature enzyme. PrA was not detected in the periplasm or medium for any of the deleted preproPrA constructs.

Glycosylation of hybrid proteins. All vacuolar proteins that were characterized are mannoproteins and undergo only limited glycosyl processing before delivery to the vacuole. As predicted from the preproPrA protein sequence, Asnlinked core oligosaccharides are added in the ER at two sites, corresponding to preproPrA residues Asn-144 and Asn-345. During transit through the ER and Golgi complex, the core groups are trimmed and then extended, resulting in a final glycosidic side chain containing 10 to 18 mannose residues $(53,54)$. This is contrasted with the secreted enzymes invertase or acid phosphatase which undergo extensive glycosyl processing in the Golgi complex; as many as 50 to 100 mannose residues are added to most of the 9 to 12 core oligosaccharides present on invertase, resulting in a hyperglycosylated protein with extensive outer chain carbohydrate $(2,54)$. This heterogeneous mixture of hyperglycosylated invertase molecules migrates as a high-molecularweight smear on SDS-polyacrylamide gels owing to the variable length of the outer mannose chains that are added to the core oligosaccharides. In contrast, the limited extension of oligosaccharide side chains on vacuolar proteins like $\operatorname{Pr} A$ and CPY resulted in a distinctly different SDS-gel pattern. These proteins migrated as discrete species on polyacrylamide gels (Fig. 7). The factors which control the extent of carbohydrate modification are not known. It is possible that a cis-acting regulatory determinant present in vacuolar proteins limits outer chain addition (21). Alternatively, vacuolar and secretory proteins may traverse separate and distinct compartments in the Golgi complex such that vacuolar proteins are not accessible to those enzymes which are responsible for outer chain elongation. To address this question, we examined the carbohydrate modification of the PEP4-SUC2 hybrid proteins (Fig. 10). The PrA-Inv hybrid proteins contained all the oligosaccharide addition sites present in wild-type invertase. With the exception of $\operatorname{PrA}$ Inv404, they did not contain either of the PrA oligosaccharide addition sites. Immunoprecipitation of the hybrid proteins in the presence of tunicamycin showed the apparent molecular weight of the proteins without carbohydrates (Fig.

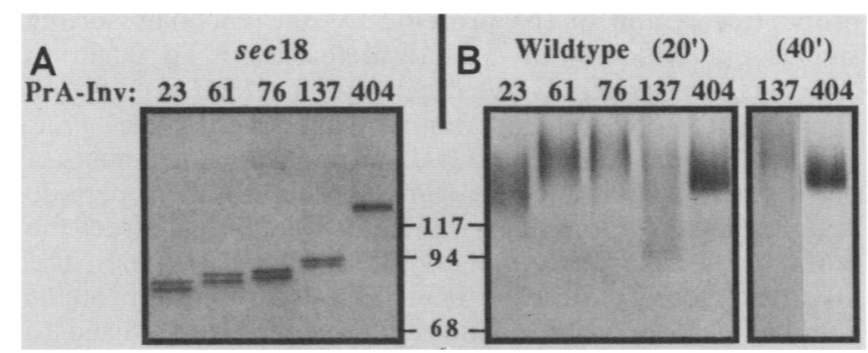

FIG. 10. Glycosyl modifications of PrA-Inv hybrid proteins. Immunoprecipitations of PrA-Inv hybrid proteins in a sec18 mutant (SEY5187) and a wild-type strain were done as described in Materials and Methods. sec18 cells expressing the indicated hybrid proteins were grown to the mid-log phase at $23^{\circ} \mathrm{C}$ and shifted to $37^{\circ} \mathrm{C}$ for $15 \mathrm{~min}$. Cells were labeled for $15 \mathrm{~min}$, and the entire cultures were then precipitated with TCA (A). Wild-type cells expressing the indicated hybrid proteins were grown at $30^{\circ} \mathrm{C}$ and labeled for $10 \mathrm{~min}$ before initiation of the chase. Samples were removed and TCA precipitated after 20 and $40 \mathrm{~min}$ of chase (B). Double immunoprecipitations with invertase antiserum were performed as described in Materials and Methods. The positions of protein standards (molecular sizes in kilodaltons) are indicated, and the number of amino acids of preproPrA fused to invertase for each of the hybrid proteins is shown above each lane.

2). In a sec18 mutant strain at the nonpermissive temperature, the hybrid proteins accumulated as core oligosaccharide-modified forms in the ER (Fig. 10). The apparent molecular weight corresponded to the molecular weight of the polypeptide plus the addition of core oligosaccharides at most of the predicted tripeptide (Asn-X-Ser/Thr) addition sites. When the hybrid proteins were immunoprecipitated from wild-type yeasts, all but one showed the migration pattern normally seen with wild-type invertase (Fig. 10). The PrA-Inv404 hybrid protein migrated as a narrow smear even after a 2-h chase. While there was some smearing in the migration pattern of the PrA-Inv404 hybrid protein, the apparent molecular weight was smaller than that of the shorter fusion proteins. This suggests that the PrA-Inv404 protein is not elongated with outer chain mannose to the same extent as the other hybrid proteins. Since there is some heterogeneity in the length of the carbohydrate chains on proteins such as CPY which have few glycosylation sites and undergo relatively limited mannose addition (54), this could account for the smearing seen with PrA-Inv404; even small differences in the number of mannoses added to each core oligosaccharide could give rise to a fairly heterogeneous population of glycoslyated proteins owing to the large number of glycosylation sites which are present on the invertase portion of the hybrid protein. All the PrA-Inv hybrid proteins with the exception of PrA-Inv404 were apparently hyperglycosylated independent of their final subcellular destination. Since they undergo outer chain carbohydrate elongation, they must enter the Golgi compartments containing the mannosyl transferases responsible for this type of modification. The sorting of PrA from other secretory proteins then apparently occurs after this point in the Golgi complex.

\section{DISCUSSION}

Recent studies of CPY have provided important information on certain aspects of protein targeting to the vacuole $(21,55)$. PreproCPY contains vacuolar sorting information at the $\mathrm{NH}_{2}$ terminus of the propeptide. Several questions about the sorting signal are immediately evident. Is it a general rule that the targeting information of vacuolar proteins is in the 
propeptide region of the protein? Do the vacuolar sorting signals exhibit common structural features? To begin to address these questions, we extended the $S U C 2$ gene fusion approach to the study of another vacuolar enzyme, PrA. This study indicated that the $\mathrm{NH}_{2}$-terminal 76 amino acids of preproPrA, comprising the signal peptide and propeptide region, contain information which is sufficient to direct the normally secreted enzyme invertase to the vacuole. The invertase activity derived from PrA-Inv hybrid proteins containing 76 or more amino acids of preproPrA fused to intact invertase was associated primarily with a purified vacuole fraction (Fig. 4). The presence of the hybrid proteins in the vacuole was confirmed by immunofluorescent staining of a yeast strain harboring the PrA-Inv404 hybrid protein (Fig. 5). Shorter PrA-Inv hybrid proteins, PrA-Inv23, PrAInv39, and PrA-Inv61, were secreted from the cell (Fig. 3). Taken together, the vacuolar delivery of PrA-Inv76 and the secretion of $\operatorname{PrA}$-Inv61 suggest that the information directing vacuolar sorting of proPrA is located between amino acid residues 61 and 76 . We cannot rule out the possibility, however, that targeting information precedes amino acid 61 but is not presented in the proper structural context to allow efficient recognition and subsequent vacuolar delivery of the PrA-Inv61 fusion protein.

The $\mathrm{N}$ terminus of preproPrA is predicted to have a signal sequence that is cleaved between amino acids 22 and 23 and is responsible for directing the protein to the ER and for initiating translocation into the ER lumen. The PrA-Inv23 hybrid protein was glycosylated and secreted from the cell (Fig. 3 and 10). This indicates the presence of a functional signal sequence within the $\mathrm{N}$-terminal 23 amino acids of preproPrA. Analysis of preproPrA and the PrA-Inv23 hybrid protein in wild type and in sec 18 and sec 62 mutant yeasts indicated that the signal peptide is cleaved from preproPrA at the level of the ER (Fig. 6). This is similar to the result seen with CPY $(4,21)$. The signal peptide, then, does not appear to play a role in vacuolar targeting beyond directing the initial translocation into the ER. Vacuolar sorting information present in the $\operatorname{PrA}$ propeptide presumably resides within amino acids 23 to 76 .

We attempted to identify common features between the vacuolar sorting information contained in proPrA and proCPY. Both proteins contain vacuolar sorting information in the propeptide region. This information is sufficient to direct the delivery of the normally secreted enzyme invertase to the vacuole. The vacuolar sorting signal in $\operatorname{PrA}$ appears, however, to map more distal to the $\mathrm{N}$ terminus than was observed for preproCPY (21). The difference in location of the vacuolar sorting information between preproPrA and preproCPY is underlined by the observation that the preproPrA $\Delta 1$ construct was sorted to the vacuole as efficiently as the wild-type protein. A corresponding deletion in preproCPY would presumably result in a significant level of missorting $(21,55)$. Several pieces of data indicate that PrA and CPY share similar pathways for vacuolar delivery. The proPrA and proCPY proteins exhibit similar processing and transport kinetics. The half-time for processing to the mature forms of both enzymes is approximately $6 \mathrm{~min}$ (Fig. 7). Since cleavage of the propeptide is an indication of vacuolar delivery, both PrA and CPY appear to transit through the secretory pathway at similar rates. In addition, targeting of PrA to the vacuole does not require the addition of carbohydrates. The protein synthesized in the presence of tunicamycin is processed to the mature enzyme (Fig. 6). This is identical to the results found for CPY and alkaline phosphatase $(7,38,48,51)$ (Fig. 6). Finally, an analysis of protein sorting in yeast $v p t$ and $v p l$ mutants which missort and secrete certain vacuolar proteins indicates that both $\operatorname{Pr} A$ and CPY utilize a common protein-sorting apparatus (45; unpublished data). We compared the amino acid sequences of preproPrA and preproCPY but were unable to identify any significant sequence homology in their vacuolar sorting signals. Since secondary or tertiary structural information may play a critical role in the sorting process, it may be difficult to define common features of the sorting signal based on an analysis of only two proteins. Significant sequence homology, for example, is also lacking among signal peptides that direct protein translocation into the ER as well as among signals that direct protein importation into mitochondria. Another possibility is that PrA and CPY contain distinct vacuolar targeting information even though they share a common delivery pathway. We have begun to analyze the location of the targeting signals in the vacuolar enzymes alkaline phosphatase and $\operatorname{PrB}(23,34)$ to compare a larger set of vacuolar sorting signals. This may allow us to detect conformational similarities as well as potential sequence biases in the overall amino acid composition of these vacuolar protein sorting signals. At present, we have not detected any obvious primary sequence homologies among this set of vacuolar proteins. Continued analysis of these and other vacuolar enzymes coupled with a more detailed analysis of the targeting signals in both PrA and CPY should provide further insight into the nature of the vacuolar sorting information.

We attempted to analyze further the role of the propeptide region by deleting part or all of this segment from the wild-type PrA protein. Deletions of 15 or more amino acids in the propeptide region led to a dramatic instability in $\operatorname{PrA}$ (Fig. 7). Crystallographic studies of pepsinogen and its proteolytic product pepsin, an aspartyl protease that has homology to $\operatorname{PrA}$, indicate that significant conformational changes occur upon activation of the zymogen (20). One major role of the PrA propeptide may be to participate in the folding of the nascent proPrA polypeptide or to stabilize the conformation of the zymogen through interactions between the propeptide and mature portions of the enzyme. Deletion of the PrA propeptide, $\Delta 24-76$, appears to destabilize mature PrA such that most of the protein is degraded. A small fraction of the $\operatorname{Pr} A \Delta$ pro polypeptides, however, must properly fold into the active enzyme since proCPY is still matured in a PrA-dependent process (Fig. 7). We also analyzed processing of $\operatorname{PrB}$, another PEP4-dependent maturation event. We found that $\operatorname{PrB}$ also is processed to its mature form by the $\operatorname{Pr} A \Delta$ pro protein (unpublished observations). A relatively small amount of $\operatorname{PrA} \Delta$ pro appears to be sufficient to allow efficient processing of at least these two vacuolar proteins. Since the signal peptide is apparently removed from PrA $\Delta$ pro in the ER (Fig. 7), any of the $\operatorname{Pr} A \Delta$ pro protein which was delivered to the vacuole would essentially be mature $\operatorname{PrA}$. This protein is presumably stable in the vacuole. The small amount that is not degraded goes on to be processed in the Golgi complex by an $\alpha-1 \rightarrow 3$ mannosyl transferase (Fig. 8) and finally is delivered to the vacuole. The propeptide therefore appears to play a role in maintaining PrA in a conformation that is competent for transit out of the ER.

While some fraction of $\operatorname{Pr} A \Delta$ pro is apparently delivered to the vacuole, it is not clear how this result should be interpreted with regard to vacuolar protein sorting. The small amount of PrA $\Delta$ pro which could be vacuolar (the amount which is stable), as well as the kinetics of transit, indicate that targeting of this mutant protein is a very 
inefficient process and may occur by an alternative sorting mechanism. This could be the result of deleting the vacuolar sorting signal which is present in the propeptide or it could be due to gross misfolding of the protein. At present, we cannot rule out the possibility that a second sorting signal is present in mature PrA. If such a signal exists, its physiological role relative to the propeptide vacuolar targeting signal is not clear. Redundancy in targeting signals, however, does appear to be a common feature of proteins destined for several other intracellular organelle targets $(3 a, 13,42)$.

Interestingly, none of the deletions in the propeptide appeared to affect propeptide processing (Fig. 9). Indeed, a deletion of amino acids 61 to 76 of preproPrA caused most of the protein to be unstable, but the small fraction of stable molecules underwent proteolytic processing to a form of the enzyme that was indistinguishable on SDS gels from the wild-type mature enzyme (data not shown). This suggests that information on the amino-terminal side of the propeptide cleavage site is not required for removal of the propeptide. Cleavage of the propeptide, then, may not be determined by recognition of a specific cleavage site but rather by the tertiary structure of the mature portion of the enzyme. The facts that CPY can be activated by trypsin (17), that it may be a substrate for cleavage by both PrA and PrB (31), that PrA can activate CPY and PrB as well as undergo autocatalysis $(19,30,61,62)$, and that there is no sequence homology among propeptide processing sites suggest that accessibility of the propeptide is the important factor in determining the cleavage site. At present, it is not known whether removal of the propeptide occurs by a single specific endoproteolytic event or by a more nonspecific proteolysis of an exposed propeptide segment. Recent evidence, however, suggests that removal of the CPY propeptide involves at least two cleavage events (31).

We showed that targeting of wild-type PrA to the vacuole does not require the addition of carbohydrates. Similarly, the PrA-Inv76, -90 , and -137 hybrid proteins were efficiently delivered to the vacuole even though they lack both of the PrA Asn-linked oligosaccharide addition sites (Fig. 1 and 4). The function of carbohydrates on vacuolar proteins is not known. The carbohydrate side chains on vacuolar proteins undergo limited mannosyl modification, but the factors controlling the extent of mannose addition are not understood. The final cellular destination does not seem to influence the extent of glycosylation, and hyperglycosylated hybrid proteins are not excluded from entering the vacuole (21) (Fig. 4 and 9). All the PrA-Inv hybrid proteins except PrA-Inv404 appeared to undergo extensive glycosyl modification (Fig. 10). PrA-Inv137 showed a kinetic delay in glycosyl modification; however, it did become hyperglycosylated like wildtype invertase. Therefore, in addition to providing information on vacuolar protein sorting signals, further analysis of other hybrid proteins also should prove useful in defining the factors involved in the regulation of glycosyl modification on vacuolar enzymes.

\section{ACKNOWLEDGMENTS}

We thank John DeModena for technical assistance, Michael W. Clark for advice on immunofluorescence techniques, and David Bedwell for critically reading the manuscript and helpful advice.

This study was supported by Public Health Service grant GM 32703 from the National Institutes of Health to S.D.E. D.J.K. was supported by a research fellowship from the Helen Hay Whitney Foundation, and L.M.B. was supported by a graduate fellowship from the National Science Foundation.

\section{LITERATURE CITED}

1. Ammerer, G., C. P. Hunter, J. H. Rothman, G. C. Saari, L. A. Valls, and T. H. Stevens. 1986. PEP4 gene of Saccharomyces cerevisiae encodes proteinase $\mathrm{A}$, a vacuolar enzyme required for processing of vacuolar precursors. Mol. Cell. Biol. 6:2490 2499.

2. Ballou, C. 1982. Yeast cell wall and cell surface, p. 335-360. In J. Strathern, F. Jones, and T. Broach (ed.), The molecular biology of the yeast Saccharomyces: metabolism and gene expression. Cold Spring Harbor Laboratory, Cold Spring Harbor, N.Y.

3. Bankaitis, V. A., L. M. Johnson, and S. D. Emr. 1986. Isolation of yeast mutants defective in protein targeting to the vacuole. Proc. Natl. Acad. Sci. USA 83:9075-9079.

3a.Bedwell, D. M., D. J. Klionsky, and S. D. Emr. 1987. The yeast $F_{1}$-ATPase $\beta$ subunit precursor contains functionally redundant mitochondrial protein import information. Mol. Cell. Biol. 7:4038-4047.

4. Blachly-Dyson, E., and T. H. Stevens. 1987. Yeast carboxypeptidase $\mathrm{Y}$ can be translocated and glycosylated without its amino-terminal signal sequence. J. Cell. Biol. 104:1183-1191.

5. Burger, M., E. Bacon, and J. Bacon. 1961. Some observations on the form and location of invertase in the yeast cell. Biochem. J. 78:504-511.

6. Casadaban, M. J., and S. N. Cohen. 1980. Analysis of gene control signals by DNA fusion and cloning in Escherichia coli. J. Mol. Biol. 138:179-207.

7. Clark, D. W., J. S. Tkacz, and J. O. Lampen. 1982. Asparaginelinked carbohydrate does not determine the cellular location of yeast vacuolar nonspecific alkaline phosphatase. J. Bacteriol. 152:865-873.

8. Clark, M. W., and J. Abelson. 1987. The subnuclear localization of tRNA ligase in yeast. J. Cell Biol. 105:1515-1526.

9. Deshaies, R. J., and R. Schekman. 1987. A yeast mutant defective at an early stage in import of secretory protein precursors into the endoplasmic reticulum. J. Cell Biol. 105: 633-645.

10. Emr, S. D., R. Schekman, M. C. Flessel, and J. Thorner. 1983. An MF $\alpha 1-S U C 2$ ( $\alpha$-factor-invertase) gene fusion for study of protein localization and gene expression in yeast. Proc. Natl. Acad. Sci. USA 80:7080-7084.

11. Goldstein, A., and J. O. Lampen. 1975. $\beta$-D-Fructofuranoside fructohydrolase from yeast. Methods Enzymol. 42:504-511.

12. Griffiths, F., and K. Simons. 1986. The trans Golgi network: sorting at the exit site of the Golgi complex. Science 234:438443.

13. Hall, M. N., and A. D. Johnson. 1987. Homeo domain of the yeast repressor $\alpha 2$ is a sequence-specific DNA-binding domain but is not sufficient for repression. Science 237:1007-1012.

14. Halvorson, H. O., and L. Ellias. 1958. The purification and properties of an $\alpha$-glucosidase of Saccharomyces italicus Y1225. Biochim. Biophys. Acta 30:28-40.

15. Haselbeck, A., and R. Schekman. 1986. Interorganelle transfer and glycosylation of yeast invertase in vitro. Proc. Natl. Acad. Sci. USA 83:2017-2021.

16. Hasilik, A., and W. Tanner. 1976. Biosynthesis of carboxypeptidase $\mathrm{Y}$ in yeast. Evidence for a precursor form of the glycoprotein. Biochem. Biophys. Res. Commun. 72:1430-1436.

17. Hasilik, A., and W. Tanner. 1978. Biosynthesis of the vacuolar yeast glycoprotein carboxypeptidase $Y$. Conversion of precursor into the enzyme. Eur. J. Biochem. 85:599-608.

18. Hasilik, A., and W. Tanner. 1978. Carbohydrate moiety of carboxypeptidase $\mathrm{Y}$ and perturbation of its synthesis. Eur. J. Biochem. 91:567-575.

19. Hemmings, B. A., G. S. Zubenko, A. Hasilik, and E. W. Jones. 1981. Mutant defective in processing of an enzyme located in the lysosome-like vacuole of Saccharomyces cerevisiae. Proc. Natl. Acad. Sci. USA 78:435-439.

20. James, M. N. G., and A. R. Sielecki. 1986. Molecular structure of an aspartic proteinase zymogen, porcine pepsinogen, at $1.8 \AA$ resolution. Nature (London) 319:33-38.

21. Johnson, L. M., V. A. Bankaitis, and S. D. Emr. 1987. Distinct sequence determinants direct intracellular sorting and modifica- 
tion of a yeast vacuolar protease. Cell 48:875-885.

22. Kaiser, C. A., and D. Botstein. 1986. Secretion-defective mutations in the signal sequence for Saccharomyces cerevisiae invertase. Mol. Cell. Biol. 6:2382-2391.

23. Kaneko, Y., Y. Tamai, A. Toh-e, and Y. Oshima. 1985. Transcriptional and posttranscriptional control of $\mathrm{PHO} 8$ expression by $\mathrm{PHO}$ regulatory genes in Saccharomyces cerevisiae. Mol. Cell. Biol. 5:248-252.

24. Kelly, R. B. 1985. Pathways of protein secretion in euckaryotes. Science 230:25-32.

25. Kubota, S., Y. Yoshida, H. Kumaoka, and A. Furumichi. 1977. Studies on the microsomal electron-transport system of anaerobically grown yeast. J. Biochem. 81:197-206.

26. Kuo, S. C., and J. O. Lampen. 1974. Tunicamycin, inhibitor of yeast glycoprotein synthesis. Biochem. Biophys. Res. Commun. 58:287-295.

27. Lenney, J., P. Matile, A. Wiemken, M. Schellenberg, and J. Meyer. 1974. Activities and cellular localization of yeast proteinases and their inhibitors. Biochem. Biophys. Res. Commun. 60:1378-1383.

28. Mage, M. G. 1980. Preparation of Fab fragments from IgG's of different animal species. Methods Enzymol. 70:142-150.

29. Mechler, B., M. Müller, H. Müller, F. Meussdoerffer, and D. H. Wolf. 1982. In vivo biosynthesis of the vacuolar proteinases A and B in the yeast Saccharomyces cerevisiae. J. Biol. Chem. 257:11203-11206.

30. Mechler, B., M. Müller, H. Müller, and D. Wolf. 1982. In vivo biosynthesis of vacuolar proteinases in proteinase mutants of Saccharomyces cerevisiae. Biochem. Biophys. Res. Commun. 107:770-778.

31. Mechler, B., H. Müller, and D. H. Wolf. 1987. Maturation of vacuolar (lysosomal) enzymes in yeast: proteinase yscA and proteinase yscB are catalysts of the processing and activation event of carboxypeptidase yscY. EMBO J. 6:2157-2163.

32. Messing, J., and J. Vieira. 1982. A new pair of M13 vectors for selecting either DNA strand of double-digest restriction fragments. Gene 19:269-276.

33. Miller, J. 1972. Experiments in molecular genetics. Cold Spring Harbor Laboratory, Cold Spring Harbor, N.Y.

34. Moehle, C. M., M. W. Aynardi, M. R. Kolodny, F. J. Park, and E. W. Jones. 1987. Protease B of Saccharomyces cerevisiae: isolation and regulation of the $P R B I$ structural gene. Genetics 115:255-263.

35. Neuman, A. J., R.-J. Lin, S.-C. Cheng, and J. Abelson. 1985. Molecular consequences of specific intron mutations on yeast mRNA splicing in vivo and in vitro. Cell 42:335-344.

36. Novick, P., C. Field, and R. Schekman. 1980. Identification of 23 complementation groups required for post-translational events in the yeast secretory pathway. Cell 21:205-215.

37. Novick, P., and R. Schekman. 1979. Secretion and cell surface growth are blocked in a temperature-sensitive mutant of Saccharomyces cerevisiae. Proc. Natl. Acad. Sci. USA 76:18581862.

38. Onishi, H. R., J. S. Tkacz, and J. O. Lampen. 1979. Glycoprotein nature of yeast alkaline phosphatase. J. Biol. Chem. 254 11943-11952.

39. Opheim, D. J. 1978. $\alpha$-D-Mannosidase of Saccharomyces cerevisiae characterization and modulation of activity. Biochim. Biophys. Acta 524:121-130.

40. Perlman, D., P. Raney, and H. O. Halvorson. 1986. Mutations affecting the signal sequence alter synthesis and secretion of yeast invertase. Proc. Natl. Acad. Sci. USA 83:5033-5037.

41. Preston, R. A., R. F. Murphy, and E. W. Jones. 1987. Apparent endocytosis of fluorescein isothiocyanate-conjugated dextran by Saccharomyces cerevisiae reflects uptake of low molecular weight impurities, not dextran. J. Cell Biol. 105:1981-1987.

42. Richardson, W. D., B. L. Roberts, and A. E. Smith. 1986. Nuclear location signals in polyoma virus large-T. Cell 44:77-
85.

43. Riezman, H. 1985. Endocytosis in yeast: several of the yeast secretory mutants are defective in endocytosis. Cell 40:10011009.

44. Rothman, J. H., C. P. Hunter, L. A. Valls, and T. H. Stevens. 1986. Overproduction-induced mislocalization of a yeast vacuolar protein allows isolation of its structural gene. Proc. Natl. Acad. Sci. USA 83:3248-3252.

45. Rothman, J. H., and T. H. Stevens. 1986. Protein sorting in yeast: mutants defective in vacuole biogenesis mislocalize vacuolar proteins into the late secretory pathway. Cell 47:10411051.

46. Rothstein, R. J. 1983. One-step gene disruption in yeast. Methods Enzymol. 101:202-212.

47. Sanger, F., F. Nicklen, and A. R. Coulson. 1977. DNA sequencing with chain-terminating inhibitors. Proc. Natl. Acad. Sci. USA 74:5463-5467.

48. Schwaiger, H., A. Hasilik, K. von Figura, A. Wiemken, and W. Tanner. 1982. Carbohydrate-free carboxypeptidase $\mathrm{Y}$ is transferred into the lysosome-like yeast vacuole. Biochem. Biophys. Res. Commun. 104:950-956.

49. Sherman, F., G. R. Fink, and C. W. Lawrence. 1979. Methods in yeast genetics: a laboratory manual. Cold Spring Harbor Laboratory, Cold Spring Harbor, N.Y.

50. Sly, W. S., and H. D. Fischer. 1982. The phosphomannosyl recognition system for intracellular and intercellular transport of lysosomal enzymes. J. Cell. Biochem. 18:67-85.

51. Stevens, T., B. Esmon, and R. Schekman. 1982. Early stages in the yeast secretory pathway are required for transport of carboxypeptidase $\mathrm{Y}$ to the vacuole. Cell 30:439-448.

52. Stevens, T. H., J. H. Rothman, G. S. Payne, and R. Schekman. 1986. Gene dosage-dependent secretion of yeast vacuolar carboxypeptidase Y. J. Cell Biol. 102:1551-1557.

53. Trimble, R. B., and F. Maley. 1977. The use of endo- $\beta-N$ acetylglucosaminidase $\mathrm{H}$ in characterizing the structure and function of glycoproteins. Biochem. Biophys. Res. Commun. 78:935-944.

54. Trimble, R. B., F. Maley, and F. K. Chu. 1983. Glycoprotein biosynthesis in yeast. Protein conformation affects processing of high mannose oligosaccharides on carboxypeptidase $\mathrm{Y}$ and invertase. J. Biol. Chem. 258:2562-2567.

55. Valls, L. A., C. P. Hunter, J. H. Rothman, and T. H. Stevens. 1987. Protein sorting in yeast: the localization determinant of yeast vacuolar carboxypeptidase $\mathrm{Y}$ resides in the propeptide. Cell 48:887-897.

56. von Heijne, G. 1986. A new method for predicting signal sequence cleavage sites. Nucleic Acids Res. 14:4683-4690.

57. Weisman, L. S., R. Bacallao, and W. Wickner. 1987. Multiple methods of visualizing the yeast vacuole permit evaluation of its morphology and inheritance during the cell cycle. J. Cell Biol. 105:1539-1547.

58. Wickerham, L. J. 1946. A critical evaluation of the nitrogen assimilation tests commonly used in the classification of yeasts. J. Bacteriol. 52:293-301.

59. Wieland, F. T., M. L. Gleason, T. A. Serafini, and J. E. Rothman. 1987. The rate of bulk flow from the endoplasmic reticulum to the cell surface. Cell 50:289-300.

60. Wiemken, A., M. Schellenberg, and K. Urech. 1979. Vacuoles: the sole compartments of digestive enzymes in yeast (Saccharomyces cerevisiae)? Arch. Microbiol. 123:23-35.

61. Woolford, C. A., L. B. Daniels, F. J. Park, E. W. Jones, J. N. van Arsdell, and M. A. Innis. 1986. The PEP4 gene encodes an aspartyl protease implicated in the posttranslational regulation of Saccharomyces cerevisiae vacuolar hydrolases. Mol. Cell. Biol. 6:2500-2510.

62. Zubenko, G. S., F. J. Park, and E. W. Jones. 1983. Mutations in PEP4 locus of Saccharomyces cerevisiae block final step in maturation of two vacuolar hydrolases. Proc. Natl. Acad. Sci. USA 80:510-514. 